\title{
A Robot Collaboration Methodology for Immediate Evacuation from Landslide
}

\author{
Taizo Miyachi, Gulbanu Buribayeva \\ School of Information Science and Technology \\ Tokai University \\ 4-1-1 Kitakaname, Hiratsuka, Kanagawa, Japan
}

\author{
Saiko Iga \\ Keio Research Institute of SFC
}

\author{
Takashi Furuhata \\ University of Utah, USA
}

\begin{abstract}
Global warming had increased the temperature of the ocean and caused new type of $\mathbf{1 1 6}$ landslides in the midnight by heavy rainfalls in Hiroshima Landslide in 2014. 74 people lost their lives. We propose a robot collaboration methodology in disaster warning that gives residents "Scenario in situation" based warnings with safe actions in a hazard map in order to help them to evacuate from large scale of landslides. The examples of concrete evacuation actions free the residents from psychological problems, such as "Normalcy Bias" and "Catastrophe Forgetting" and also enable them to immediately take safe actions. We also discuss refugees support simulation by showing the warning hazard map on a screen in a prototype of robot.
\end{abstract}

Keywords- immediate landslide evacuation; robot collaboration; scenario in situation based warning; safe actions in a hazard map

\section{INTRODUCTION}

Global warming causes floods and landslides by new types of heavy rainfall in the world. It also causes (i) serious heavy rainfall in the mid-night, (ii) strong typhoon, and (iii) sudden localized torrential rainfall "Guerrilla-heavy-rainfall (GHR)," etc. There are more than 520,000 dangerous points in landslide hazard in Japan since most ground in Japan consists of soil of weathered rock like "Masado" and volcanic ashes. Heavy rainfalls have caused serious damages in both big city and local areas by landslides. 116 landslides happened and 74 persons lost their lives by "Hiroshima landslides 2014" in Hiroshima city (See Fig.1) and 35 persons lost their lives by "Izu-Ohshima landslides 2013" in Izu-Ohshima small island in Japan. Residents should study new types of disasters and safely evacuate from the landslides even either in the midnight or in a Typhoon.

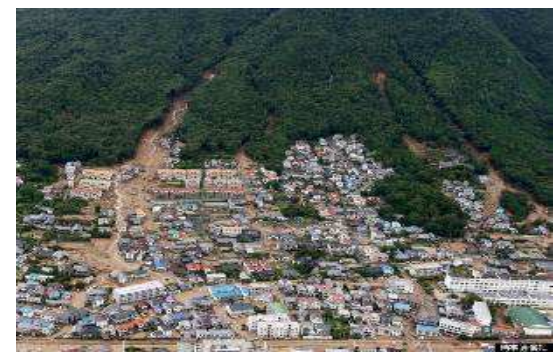

FIGURE I. HIROSHIMA LANDSLIDE 2014[1]

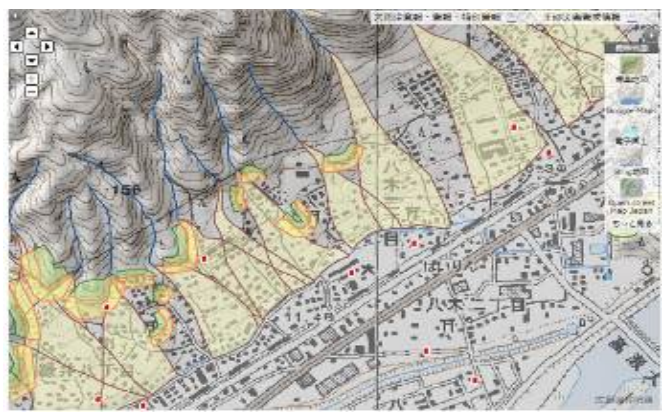

FIGURE II. LANDSLIDE HAZARD MAP IN HIROSHIMA CITY [2].

We propose a robot [7] collaboration methodology in disaster warning for residents in order to study features of landslides and to survive by "scenario in situation" based warning with effective hazard maps that include concrete safe actions in both prior evacuation and evacuation when the landslides happen.

\section{HARD DECISION MAKING IN SEVERE ENVIRONMENTS IN THE NIGHT}

A resident should quickly evacuate with his/her family to a safe place in case of land-slide. A human usually can neither consider well nor quickly make a right decision when he/she is suddenly awaken in the mid-night. There are mainly eight reasons. (a) A resident is half asleep, (b) unexpected scale of disaster, (c) cluttered information of safe places close to the home, (d) tough evacuation environments with heavy rain and invisible bottoms in streams with mad, (e) ability of walking in heavy rain, thunders, and severe routes, (f) psychological disorder (Normalcy Bias), (g) delay of warning by lack of officers, and (h) catastrophe forgetting. Strange reasons are next four reasons.

(c) Cluttered information of safe places close to the house. There is no discrimination between flood shelters and landslide shelters in hazard maps of the local governments. Residents misunderstand a dangerous shelter as a safe shelter. They cannot find safe place cloth to their house in dangerous situations.

(f) Psychological disorder (Normalcy Bias: NB [4]). "Normalcy bias" refers to a mental state that a person 
underestimate both the possibility of a disaster occurring and its possible effects when he/she faces a disaster. He/she can avoid a panic by NB. A resident in an area where landslides have never happened for several ten years believes that the area is safe area although its geographical features are as same as those in dangerous areas. The resident also misunderstands that his/her house are built a safe ground since landslide has not happened when large scale of landslide happened in remote area that locates several kilo-meters away from his/her house. He/she thinks that his/her house might be safe since the position of his/her house is not just under a mountain stream. A resident near hillside expects to think he/she is special and lives in a safe position for landslides although all people in the lower ground are not safe in case of giant tsunamis.

(g) Delay of warning by lack of sensors. The landslide warnings were delayed because of much jobs of public official that in charged in landslide warning. He/she must estimate an expected a change of height of water in a mountain streams with no water gauge, and answer frequent telephone inquiries, etc.

(h) Catastrophe forgetting [5]. A resident usually gathers many kinds of disaster information in remote areas and considers the effects for his/her jobs and family's activities. The resident tended to reduce his/her awareness about serious unexpected damages and could not notice a new type of severe landslide since mind of the resident was already occupied by such massive information.

\section{III. "SCENARIO IN SITUATION" BASED WARNING FOR PRE- LEARNING BY AUTONOMOUS ROBOTS}

Weather prediction is accurate in Japan although earthquakes cannot be predicted. Therefore residents think that they can safely evacuate from landslides. However global warming has drastically changed the nature near Japan and caused large scale of many landslides with torrential rainfalls by "back building [3]" rain-bands over a limited area in the midnight or in the evening in Japan. Such large scale of landslide becomes a serious problem in many big cities in Japan since such big cities have already expanded the residential area to thousands of mountain streams in the hillsides that consist of weak "Masado" and volcanic ash.

In these days, many kinds of tasks, such as risk management of stocks, sales/ customer management in a conveyor belt sushi bar, etc. can be well done by robots. Difficult tasks in unpredictable change in both environments and resident's minds need more information including direct sensor data and safe actions corresponding to the many kinds of situations.

We propose a robot collaboration methodology for disaster warning that gives residents "Scenario in Situation" Based (SSB) warnings with safe actions in a hazard map in order to help them to evacuate from large scale of landslides.

(1) Collaboration between residents and two kinds of robots.

Distributed robots in the mountain streams can discover the sign of landslides and send to communication robots in homes and supermarkets, etc. A communication robot can send the signs to the other communication robots when a resident discovers it. Owners of communication robots can quickly know the sign by such collaborations between residents and two kinds of robots.

(2) Effective distribution of "scenario in situation" based warnings by robots

Weather prediction of heavy rain is accurate in Japan. Residents can choose an evacuation time of landslide corresponding to the house position in a fan shape of dangerous place.

(i) Prior evacuation several hours before a landslide

(ii) Evacuation when the sign is discovered

(iii) Evacuation when a landslide happens

Prior evacuation with "scenario in situation" based pre-learning

We propose "scenario in situation" based pre-learning. An autonomous robot naturally shows residents hazard maps with safe actions in landslides in daily life as an easy prior learning system when it interacts with either owners in home or customers in supermarkets, etc. This is an easy and effective distribution methodology since residents in a safe area neither expect to go to either City Hall or community centres to see hazard maps nor access digital hazard maps in city home page. The prior learning by hazard maps is very important in order to make a resident remind the concrete relationships among resident's house, dangerous areas, safe places, a safe evacuation direction, and routes to a safe place in a short time. Residents also study the difficulty of walking to the safe place in the night, and how to survive, etc. Such important information would be thought through properly while sleeping. They can effectively proceed with prior evacuation before a large scale of landslide.

Evacuation when the sign is discovered by residents or sensor robots.

Resident can acquire the last chance to survive a few minutes before a landslide if either residents or sensor robots could discover the omen of large scale of landslide in the smell of rotten leaves or in mountain streams. We propose "scenario and situation" based landslide warning with hazard map that includes concrete safe actions by autonomous robot network [9] in order to avoid the worst cases. The hazard maps show residents how to take effective actions within a few minutes in the first evacuation when the omen could be discovered before the landslide. A safe direction, a safer next house, a safe place close to the home, a route to the safe place, and safe actions can be easily understood in a short time in order to survive corresponding to resident's position in a fan shape of dangerous place. Many kinds of survival stories at the position in the first evacuation would be provided by survived people. Outdoor safer places are next two.

(a) Outdoor. Move in perpendicular to the avalanche and to a next house. About 50 meters moving in perpendicular to the avalanche increases the possibility of survival. Friends in the next house are important. 
(b) Outdoor. Move to a three stories solid building or higher.

Example 1. A person moved to a next house and survived although his/her house was swallowed and broken by ARSE.

\section{Evacuation when a landslide comes to the house.}

A resident should take next safe actions in the house within a minute.

Indoor. Move up to 2nd floor or higher. Move to valley side room and to the window in the room.

Example 2. Survive on the second floor. A family that a father pushed a son and a grandmother on a stair to the second floor could survive avoiding violent avalanches on the first floor. If the evacuation would be late ten seconds the family are killed by the avalanche.

Example 3. A survival in a valley side room on second floor. A child in hill-side room on second floor was swallowed by the avalanche but a child stay at the window in a room on second floor at the other side of hillside could survive.

\section{EXPERIMENT}

Many victims in Hiroshima Landslide 2014 did not feel danger by the heavy rainfall warning since they tended to believe their residential areas have been safe although the other similar area had serious damages fifteen years ago. We simulated whether subjects feel the danger of landslide such that he/she has to leave his/her house or move to a safer place in the house or not.

ConditionsCo. Suppose, the subject lives in a landslide hazard area ("avalanche of rocks and earth"). The landslide warning has already been issued.

Devices. (1) TV, (2) mobile phone, and (3) robot stands next to the subject

Case 1. Severe rainfall warnings and a landslide warning in text were shown on a screen of TV and an announcer of TV tells the residents the warnings. A subject does not evacuate.

Case 2. A mobile phone produces loud buzzer of landslide warning for a subject and shows the warnings in text on a screen of the mobile phone. The subject evacuates by the warning (See Fig. 3).

Case 3. An autonomous robot sometimes showed a safe route to a safe place in the hazard map in daily life. The robot produces loud sound of avalanche of rocks and earth warnings for a subject and shows the safe route to a safe place in the hazard map. The subject evacuates by the warning (See Fig. 3).

Subjects: Group1. 26 persons between 18 and 24 years old.

Group2. 53 persons between 18 and 22 years old.

Group3. 6 persons between 24 and 63 years old.

Test. Difference of "avalanche of rocks and earth warnings" among (1) video and the warnings in text on TV, (2) warning sound and warnings in text on mobile phone, and (3) warning sound and a safe route to a safe place in the hazard map on a screen of autonomous robot.

\section{OperationsO2.}

(1) A subject watches and hears explanations in three pictures on TV.

(2) A subject watches and hears explanations in text on a screen of mobile phone.

(3) A subject watches and hears explanations of safe route to a safe place and safe actions in the hazard map on a screen of the robot.

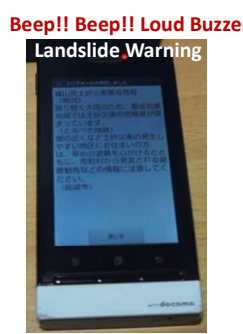

(a)

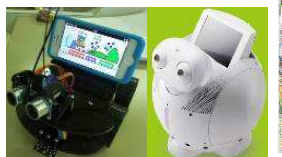

(b)

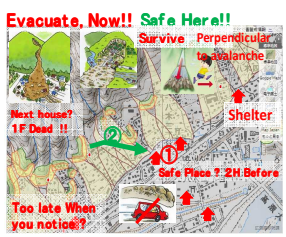

(c)
FIGURE III. LANDSLIDE WARNING BY A MOBILE PHONE AND AN AUTONOMOUS ROBOT. (A. LANDSLIDE WARNING BY MOBILE PHONE[6], B. AN IMAGE OF ROBOT [7], C. "SCENARIO IN SITUATION" BASED LANDSLIDE HAZARD [8,9]].

Question1. "Which case do you feel the mortal danger and evacuate?"

Answer1. Groupe1. Case 1: 18, Case 2: 2, Case 3: 6 (See Fig. 4)

(person) Groupe2. Case 1: 41, Case 2: 4, Case 3: 6, Other: 2 (See Fig. 4)

Groupe3. Case 1: 2, Case 2: 1, Case 3: 3 (See Fig. 4)

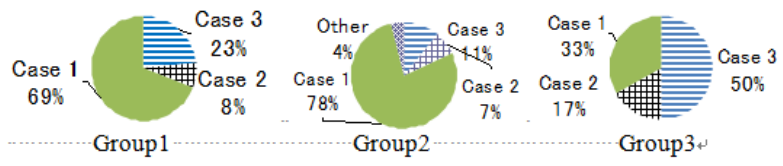

FIGURE IV. EFFECTIVE WARNING IN A HAZARD MAP.

Interview1. Why do you feel the mortal danger in the case that you chosen?

\section{Groupe1.}

Real time data of new excellent technology by ultrasonic radar made me trust the omen. I will consider SSB warning as a safe evacuation.

(1) New technology might let me know useful data for the survive

(2) Prior learning let me know the important knowledge and useful concrete safe places. The combination between prior learning and the warning can be trusted in serious situation.

\section{Groupe2.}

(3) Two persons felt the mortal danger since they have experiences in their villages in hillside. They always evacuated to a safe place several hours before the disaster when the warnings were issued by any terminals. 
(4) Two persons could trust an exact safe place and a safe route to there in the hazard map. Such concrete safe information becomes the proof of reliable information. They considered SSB warning as one option for the survival.

\section{Groupe3.}

(5) A subject always trusts only the information shown by trusted organizations.

(6) Trusted information on the hazard map should be useful in complex geometric areas.

(7) A subject expects to survive. He trusted the warnings from either a mobile phone or a robot.

We could ensure the effectiveness of the robot collaboration methodology with SSB prior learning and SSB warnings although most subjects except two persons live in safe areas.

\section{Discussion}

People that have many kinds of experiences could be more flexible than young people in order to reconfirm the safety to survive. Most young people that were enjoying safe life could not reconsider the current safe environments.

D1. Most subjects except two persons live in safe areas and have never suffered from serious damages of great disasters although some of them live near rivers or hillside. They trusted the safety for disasters in their cities. Acoustic signs in strange sounds make them to be aware of serious dangers. An acoustic sign with accurate direction like an ultrasonic beam can guide them to a safe direction.

D2. One resident detected the high water face in a river and called a telephone to friends in the village. This observation and human network saved their lives. Robots with water height gauge can be built by robot sensor networks.

D3. Guide system should consider traffic jams in the day time. The guide system should show safe routes in the night since it becomes difficult for pedestrians to find barriers and invisible dangers both on the roads and in streams with mad. A driver should choose safer road in heavy rain since the driver happen to drive into an underpass in deep flood.

\section{CONCLUSION}

We propose a robot collaboration methodology for prior evacuation, first evacuation, and evacuation with "Scenario in situation" based warning (SSB) including safe actions in the hazard maps to survive. We showed how to easily proceed with prior learning for safe prior evacuation and two kinds of immediate evacuations in order to avoid the psychological problems, such as strong $\mathrm{NB}$ and $\mathrm{CF}$ by autonomous robot with SSB. We could ensure the effectiveness of the robot collaboration methodology with SSB prior learning and SSB warnings although most subjects except two persons live in safe areas.

\section{REFERENCES}

[1] The Jiji Press, "Hiroshima Sediment Disaster," "http://www.huffingtonpost.jp/2014/08/20/hiroshimalandslide_n_56937 07.html."
[2] Hiroshima Prefecture, "Sediment Disaster Dangerous Points," Sediment DisasterPortalHiroshima,"http://www.sabo.pref.hiroshima.lg.jp/portal/m ap/kiken.aspx," 2014.

[3] H.B.Bluestein, and M.H.Jain, "Formation of mesoscale lines of pirecipitation: severe squall lines in Oklahoma during the spring," Journal of the Atmospheric Sciences, 1985.

[4] Kahneman, D. and Tversky, A., "Prospect theory: An analysis of decisions under risk," Econometrica, 47(2), 313-327, (1979).

[5] McCloskey, M. and Cohen, N., "Catastrophic interference in connectionist networks: The sequential learning problem." in G. H. Bower (ed.) The Psychology of Learning and Motivation: Vol. 24, 109164, NY: Academic Press, 1989.

[6] Kurotetsu Kaicho, "A scene of receiving heavy rainfall warning (area mail) by mobile phone 20-July-2014," "https://www.youtube.com/watch?v=aTh0dLZpWPc,"

[7] Kawasaki City, "Communication robot. Friends of Human, Kawasaki science world," “ http://www.keins.city.kawasaki.jp/content/ksw/1/ksw1_036-043," 2005

[8] SPC, "Illustration library in NPO Sediment Disaster Prevention Publicity Center," "http://www.sabopc.or.jp/library/illust01.html"

[9] Gulbanu Buribayeva and Taizo Miyachi, "Robots Collaboration Based on Cloud Robotics System for Daily- Emergency Life," WEBIST2014, 2014. 